\title{
Experimental Investigation of Molten Salt Droplet Quenching and Solidification Processes of Heat Recovery in Thermochemical Hydrogen Production
}

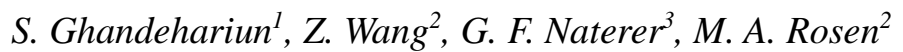 \\ ${ }^{1}$ Faculty of Engineering, University of Alberta \\ ${ }^{2}$ Faculty of Engineering and Applied Science, University of Ontario Institute of Technology \\ ${ }^{3}$ Faculty of Engineering and Applied Science, Memorial university of Newfoundland \\ Email: samane@ualberta.ca
}

\section{Abstract}

This paper investigates the heat transfer and x-ray diffraction patterns of solidified molten salt droplets in heat recovery processes of a thermochemical $\mathrm{Cu}-\mathrm{Cl}$ cycle of hydrogen production. It is essential to recover the heat of the molten salt to enhance the overall thermal efficiency of the copper-chlorine cycle. A major portion of heat recovery within the cycle can be achieved by cooling and solidifying the molten salt exiting an oxygen reactor. Heat recovery from the molten salt is achieved by dispersing the molten stream into droplets. In this paper, an analytical study and experimental investigation of the thermal phenomena of a falling droplet quenched into water is presented, involving the droplet surface temperature during descent and resulting composition change in the quench process. The results show that it is feasible to quench the molten salt droplets for an efficient heat recovery process without introducing any material imbalance for the overall cycle integration.

Keywords: hydrogen production; thermochemical water splitting; heat recovery; molten salt

\section{Introduction}

Worldwide energy demand is increasing rapidly due to the continuing increase in world population and the desires of developing countries to improve their living standards. A large portion of the world energy demand is met by fossil fuels, because of their availability and convenience. However, it is expected that fossil fuel production worldwide may peak in about 15 years and thereafter begin to decrease [1]. Also, the environmental damage caused by fossil fuel usage and their combustion products is a major problem [2, 3]. Hydrogen is a potentially major solution to the problems of climate change. It burns cleanly to produce water without emissions. It is used in fuel cells to generate electricity directly. Its energy content per unit 
mass is 2.5 times higher than that of any other conventional fuels [3, 4]. Therefore, hydrogen is a promising

31

32

33

34

energy carrier and storage medium for renewable energy resources [3-7]. Lu et al. [8] analyzed the feasibility of an optimal cascade hydropower system using hydrogen, produced from water electrolysis, as an energy storage medium. The authors showed that by using hydrogen production and storage in hydropower stations, more water resources can be used for electricity and hydrogen production, hence the amount of unused water is reduced and electricity generation reliability (EGR) is improved [8]. The economic viability of hydrogen production and storage from excess electricity in a $50 \mathrm{MW}$ wind power plant was investigated by Kroniger and Madlener [9]. Their results showed that the power-to-fuel plant could be operated profitably at a hydrogen price of over $0.36 € / \mathrm{m}^{3}$ with $100 \%$ utilization of the electrolyzer if the hydrogen is directly marketed instead of using it to store and re-generate electrical energy [9]. Coupled operation of a wind turbine and electrolyzer was investigated by Sarrias-Mena et al. [10]. The authors evaluated four different electrolyzer configurations under variable wind speeds and grid demand.

Most of the hydrogen currently produced in the world is derived from fossil fuels through different types of reforming processes $[11,12]$. Developing a sustainable, large-scale, low-cost method of hydrogen production from energy sources other than fossil fuels is required to reduce GHG emissions and accelerate the transition to a clean future. Water electrolysis and thermochemical cycles, using various heat sources, are alternative methods for sustainable hydrogen generation [13-15]. Han et al. [16] reported the effect of various operating conditions and design parameters on the performance of proton exchange membrane (PEM) electrolyzer cells. Their results show that PEM electrolyzer cell performance improves with a decrease in electrode thickness and membrane thickness due to lower diffusion overpotential and ohmic losses. At a current density of $1.5 \mathrm{~A} / \mathrm{cm}^{2}$, the performance loss due to the interfacial resistance between the electrode and the membrane contributes $31.8 \%$ of the total ohmic loss. An experimental study on hydrogen production from a $200 \mathrm{~W}$ solid oxide stack working in a reverse mode was presented by Penchini et al. [17].

The influence of steam dilution, water utilization and operating temperature on conversion efficiency and the stack's thermal balance was evaluated. The tests were performed at three different operating 
temperatures over a range of steam inlet concentrations from $50 \%$ to $90 \%$ and water utilization up to $70 \%$.

56 The net flows up to $2.4 \mathrm{ml} /\left(\mathrm{min} \mathrm{cm}^{2}\right)$ of hydrogen and $1.2 \mathrm{ml} /\left(\operatorname{min~} \mathrm{cm}^{2}\right)$ of oxygen were measured [17].

A thermochemical cycle has a potentially higher overall efficiency compared to water electrolysis as heat is used directly to generate hydrogen to avoid the thermal energy losses in the heat-to-electricity conversion process. Water electrolysis has an overall heat-to-hydrogen efficiency of about $24 \%$, based on the higher heat value of hydrogen, while thermochemical cycles can reach a heat-to-hydrogen efficiency up to about 50\% [18].

A thermochemical water splitting process includes decomposition of water into oxygen and hydrogen using only heat in a fully thermochemical cycle, or a combination of electricity and heat in a

64 hybrid cycle. The net reaction is as follows:

$$
\mathrm{H}_{2} \mathrm{O}(\mathrm{l}) \rightarrow \mathrm{H}_{2}(\mathrm{~g})+1 / 2 \quad \mathrm{O}_{2}(\mathrm{~g})
$$

Several thermochemical water splitting cycles, using various sources of energy, have been studied in the past [19-23]. The sulfur-iodine thermochemical cycle, in which solar energy is used for the 67 decomposition of sulphuric acid, was investigated by Huang and Raissi [24]. Xinxin and Kaoru [25] studied the sulfur-iodine (S-I) cycle for hydrogen production using nuclear energy. Energy and economic assessment of an industrial plant for hydrogen production by a sulfur-iodine thermochemical cycle was presented by Liberatore et al. [26]. The efficiency of the thermochemical cycle by itself was about 34\%,

71 based on the higher heat value. If this value is associated with the electrical energy production, including 72 the efficiency of the solar plants, the total heat-to-hydrogen efficiency was obtained to be $21 \%$. Varsano et 73 al. [27] analyzed a sodium manganese mixed ferrite thermochemical cycle with a solar reactor receiver 74 packed with pellets of a reactive mixture to investigate the feasibility of the process. The temperature at 75 which the reactor operates is nearly constant within the range of $700-800^{\circ} \mathrm{C}$. About $130-460$ micromole 76 hydrogen per gram of mixture is produced during one hour operation of the reactor. An iron-chlorine 77 thermochemical cycle was studied by Canavesio et al. [28]. The theoretical and experimental study was 78 carried out at a laboratory scale to investigate the reaction pathway and the kinetics of the thermochemical 79 cycle in order to improve its overall performance in terms of energy efficiency and hydrogen yield. Xu and 
Wiesner [29] presented a conceptual design of a two-step iron oxide cycle for production of hydrogen.

81 Molten FeO is used as a storage and heat transfer medium. After five days, the hydrogen production was 82 stabilized at $7 \mathrm{~kg} / \mathrm{min}$.

Alternative thermochemical cycles of hydrogen production were evaluated by Lewis et al. [30-32].

84 Their results showed that the copper-chlorine cycle is chemically possible and feasible concerning 85 engineering aspects and energy efficiency. Dincer and Balta [33] have discussed several cycles for 86 hydrogen production from nuclear energy. The $\mathrm{Cu}-\mathrm{Cl}$ thermochemical cycle was shown a promising cycle

87 for nuclear-based hydrogen production. Recent advances in thermochemical cycles of hydrogen production, 88 using non-fossil energy sources such as nuclear or solar, were reported by Rosen [18]. The copper-chlorine 89 cycle was shown to have significant potential because of the lower temperature requirement for heat 90 supplies compared to most other thermochemical cycles. It is necessary to improve the overall thermal 91 efficiency of the $\mathrm{Cu}-\mathrm{Cl}$ hydrogen production method. Therefore, heat recovery within the cycle is an 92 essential part of the process. This paper investigates a direct contact heat recovery process in the copper93 chlorine cycle of hydrogen production.

94

\section{Copper-chlorine Cycle for Hydrogen Production}

96 The copper-chlorine cycle decomposes water into oxygen and hydrogen, through intermediate copper and 97 chloride compounds, in a closed loop in which all chemicals are recycled continuously. There are three 98 variations of the $\mathrm{Cu}-\mathrm{Cl}$ cycle, based on the number of main chemical reactions: three steps, four steps, and 99 five steps. The schematic of the four step cycle is shown in Fig. 1.

$101 \mathrm{CuCl} / \mathrm{HCl}$ electrolysis:

$$
2 \mathrm{CuCl}(\mathrm{aq})+2 \mathrm{HCl}(\mathrm{aq}) \rightarrow \mathrm{H}_{2}(\mathrm{~g})+2 \mathrm{CuCl}_{2}(\mathrm{aq})
$$

102 where oxidation of copper(I) chloride takes place during an electrochemical reaction, in the presence of 103 hydrochloric acid to produce copper(II) chloride and hydrogen. 
105 is dried to produce solid $\mathrm{CuCl}_{2}$ particles:

$$
\mathrm{CuCl}_{2}(\mathrm{aq}) \rightarrow \mathrm{CuCl}_{2}(\mathrm{~s})
$$

The $\mathrm{CuCl}_{2}$ particles are then moved to the third step which is hydrolysis, and reacted with superheated steam to perform copper oxychloride hydrochloric $\mathrm{HCl}$ and $\mathrm{Cu}_{2} \mathrm{OCl}_{2}$ :

$$
2 \mathrm{CuCl}_{2}(\mathrm{~s})+\mathrm{H}_{2} \mathrm{O}(\mathrm{g}) \rightarrow \mathrm{Cu}_{2} \mathrm{OCl}_{2}(\mathrm{~s})+2 \mathrm{HCl}(\mathrm{g})
$$

Step 4 is the oxygen production step where solid particles of copper oxychloride decompose into molten copper(I) chloride and oxygen:

$$
\mathrm{Cu}_{2} \mathrm{OCl}_{2}(\mathrm{~s}) \rightarrow 2 \mathrm{CuCl}(\mathrm{l})+1 / 2 \mathrm{O}_{2}(\mathrm{~g})
$$

Several variations of copper-chlorine cycles with different numbers of steps and methods of grouping were compared, and major features of the cycles with different numbers of steps were discussed by Wang et al. [34]. A detailed kinetic study of the hydrogen and oxygen production reactions in the $\mathrm{Cu}-\mathrm{Cl}$ cycle was presented by Serban et al. [35]. Canadian advances in nuclear-based production of hydrogen by the $\mathrm{Cu}-\mathrm{Cl}$ cycle were presented by Naterer et al. [36-39]. Thermophysical properties of copper compounds in the Cu$\mathrm{Cl}$ cycle were studied by Zamfirescu et al. [40]. The environmental impacts of the $\mathrm{Cu}-\mathrm{Cl}$ cycle were presented by Ozbilen et al. [41] using life cycle assessment.

Hydrolysis of $\mathrm{CuCl}_{2}$ into $\mathrm{Cu}_{2} \mathrm{OCl}_{2}$ and $\mathrm{HCl}$ using a spray reactor was investigated by Ferrandon et al. [42]. It was shown that a counter-current flow reactor results in a significantly higher yield of $\mathrm{Cu}_{2} \mathrm{OCl}_{2}$ compared to a co-current flow, due to enhanced mass transfer. Naterer et al. [43] examined the evaporative drying of aqueous copper(II) chloride $\mathrm{CuCl}_{2}$ droplets in the copper-chlorine cycle. The results showed that benefits of flashing the solution to enhance drying were relatively minor, compared to evaporative drying in the spray drying process.

\section{Heat Recovery for Thermal Integration of the $\mathrm{Cu}-\mathrm{Cl}$ Cycle}

Regardless of the variations of the $\mathrm{Cu}-\mathrm{Cl}$ cycles, molten salt of $\mathrm{CuCl}$ is produced in the oxygen production step, and aqueous $\mathrm{CuCl}$ (i.e. $\mathrm{CuCl}$ dissolved in the hydrochloric acid) is used in the hydrogen production 

in all types of $\mathrm{Cu}-\mathrm{Cl}$ cycles linking the oxygen and hydrogen production steps. The processing of $\mathrm{CuCl}$ will significantly affects the efficiency of the copper-chlorine cycle and the complexity of the process integration from the perspectives of the integration of thermal energy and material flows. This paper will examine the fundamental phenomena in the molten salt thermal energy recovery process, and the influence of the heat recovery method on the integration of material flows.

Heat recovery within the copper-chlorine cycle is crucial to the efficient performance and the 134 overall viability of the cycle [36-39]. The heat requirements of different steps of the five-step copper135 chlorine cycle were evaluated by Naterer et al. [44]. The authors evaluated the heat matching between the 136 steps of the copper-chlorine cycle so as to recover as much heat as feasible and minimize the net heat 137 requirement of the $\mathrm{Cu}-\mathrm{Cl}$ cycle. It was shown that the thermal efficiency of the $\mathrm{Cu}-\mathrm{Cl}$ cycle improves 138 significantly if all the heat released is recovered in the cycle [44]. analysis was used to determine how much heat can be recovered within the cycle, and where in the cycle the recovered heat can be used. About $18 \%$ of the total required heat of the copper-chlorine cycle can be obtained by cooling $\mathrm{HCl}, \mathrm{O}_{2}$, and molten $\mathrm{CuCl}$. About $88 \%$ of the total heat recovery can be achieved by cooling molten $\mathrm{CuCl}$ exiting the oxygen reactor step of the cycle at about $530^{\circ} \mathrm{C}$. Therefore, the focus of 144 heat recovery is on heat recovery from molten $\mathrm{CuCl}$. Since the melting point of $\mathrm{CuCl}$ is about $430^{\circ} \mathrm{C}$, solidification occurs as molten $\mathrm{CuCl}$ cools. A comparison of various processes for heat recovery from molten copper (I) chloride was explored by Ghandehariun et al. [46]. It was shown that a portion of heat recovery can be used to produce superheated steam required for the hydrolysis step of the cycle. However, 148 the remainder can be used only in the drying step due to its lower temperature [46]. contact heat transfer equipment such as a shell and tube heat exchanger, molten $\mathrm{CuCl}$ flows through an 151 inner pipe while the coolant flows through the outer pipe [47]. In a direct contact heat recovery process, 152 molten $\mathrm{CuCl}$ can be first dispersed into droplets that subsequently fall down to a water bath for quenching, 
and at the same time the generated steam flows upwards to form a counter current contact with the falling

154 droplets. The droplets are cooled and solidified during the descent and quench. Heat transfer from the 155 droplet occurs by three main mechanisms: convection heat transfer, mass transfer, and radiation heat 156 transfer.

cycle. As presented previously, instead of the molten $\mathrm{CuCl}$, the solidified $\mathrm{CuCl}$ is used in the downstream electrolysis step. This suggests that the shell and tube heat recovery system may not be preferable, because the solidification is not desirable inside the tube or shell. The processing of solidified $\mathrm{CuCl}$ in a shell and tube heat exchanger is very challenging. Direct contact with a water quench was selected as the heat recovery method in this paper. The $\mathrm{CuCl}$ exiting the heat recovery system (i.e. solidified $\mathrm{CuCl}$ ) is used in another part of the cycle (i.e. electrolysis step). Therefore, it is essential to avoid any possible undesirable chemical reactions during the direct quench process. In addition to obtaining fundamental heat transfer data, this paper will also investigate the feasibility of using the direct quench process from a chemical composition perspective.

\section{Heat Transfer Formulation}

169 The velocity of a falling droplet is evaluated by solving Newton's second law of motion for a freely-falling 170 droplet as follows:

$$
m_{d}\left(\frac{d v}{d t}\right)=m_{d} g\left(1-\frac{\rho_{g}}{\rho_{d}}\right)-\frac{1}{8} \pi d^{2} \rho_{g} C_{D} v^{2}
$$

171 where $C_{D}$ is the drag coefficient and calculated from the following correlation over $R e<3 \times 10^{5}$ [48].

$$
C_{D}=\frac{24}{R e}\left(1+0.15 R e^{0.687}\right)+\frac{0.42}{1+4.25 \times 10^{4} R e^{-1.16}}
$$

172 The temperature profile in the droplet is assumed to be uniform and resistance to heat transfer exists only

173 in the surrounding gas. The rate of temperature change is modeled by a heat balance between the droplet 174 and the surrounding gas: 


$$
m_{d} c_{p, d} \frac{d T_{d}}{d t}=-\dot{q}_{c}
$$

175 where $\dot{q}_{c}$ represents convective heat transfer from the droplet surface. It can be expressed as:

$$
\dot{q}_{c}=h_{c} A\left(T_{d}-T_{\infty}\right)
$$

176 where $h_{c}$ is the convection heat transfer coefficient, $A$ is the droplet surface area, and $T_{d}$ and $T_{\infty}$ are the

177 droplet and ambient gas temperatures, respectively. The convection heat transfer coefficient is found by:

$$
h_{c}=\frac{N u k_{g}}{d}
$$

178 where $\mathrm{Nu}$ is the Nusselt number, $k_{g}$ is the thermal conductivity of the ambient gas, and $d$ is the diameter of 179 the droplet.

181 falling liquid drops:

$$
N u=2+0.6 \operatorname{Re}^{\frac{1}{2}} \operatorname{Pr}^{\frac{1}{3}}
$$

182 where $R e$ is the Reynolds number and $P r$ is the Prandtl number. Solving the above equations with the initial 183 condition $T_{d}(0)=T_{i}$ yields:

$$
\frac{T_{d}-T_{\infty}}{T_{i}-T_{\infty}}=\exp \left(-\frac{h_{c} A}{m_{d} c_{p, d}} t\right)
$$

\section{Experimental Study}

\subsection{Apparatus and Procedure}

187 The purity of $\mathrm{CuCl}$ in the experiments is $99.9 \%$. The melting point is $420^{\circ} \mathrm{C}$. In the experiments, solid 188 powder of $\mathrm{CuCl}$ was placed into an inclined pipe and heated to melt $\mathrm{CuCl}$ inside the pipe. The $\mathrm{CuCl}$ flowed 189 out and formed molten salt droplets. In addition to using the inclined pipe to generate molten droplets, a 190 heating mantle was also used to produce molten $\mathrm{CuCl}$ and then molten salt was poured into a small container

191 with a nozzle at the bottom. The nozzle diameter was changed so that different droplet diameters could be 192 obtained. The molten droplets exiting the nozzle fell through air and eventually into a water vessel. The 

measured by a Flir SC5600 infrared camera.

The droplets fell through the air and then released heat into a vessel of water. The water depth in 196 the quench cell was $25 \mathrm{~cm}$, and the descent distance from the pipe exit to the water level could be adjusted 197 in the range of $60-120 \mathrm{~cm}$. An infrared thermal imaging system was used to measure the temperature of the 198 droplets during the descent. At the same time, a visible light camera was used to record the shape and 199 quench phenomena of the droplets.

To investigate the possible reactions between copper(I) chloride and water or air, two sets of experiments were performed. In one set of experiments, the solidified product in water was collected and 202 dried in air. In the other set of experiments, the solidified material was kept in a small container filled with 203 water, in a nitrogen glove box, to avoid exposure to air. The composition of each prepared sample was then 204 determined by an X-ray diffractometer to examine the existence of undesirable chemical reactions during 205 the quench process. The experiments were implemented in a fume enclosure to avoid the risk of $\mathrm{CuCl}$ 206 hazards.

\section{$208 \quad 4.2$ Temperature measurements}

209 An infrared (IR) imaging technique was used in the experiments to measure the surface temperature of a 210 droplet. An infrared camera receives radiation from surroundings and the target object. Both of these 211 radiation components become attenuated passing through the atmosphere. The atmosphere itself also

212 radiates some energy, which causes the background temperature in the readings of the infrared camera. The 213 total radiation received by the infrared camera is espressed as:

$$
\mathrm{W}=\mathrm{W}_{1}+\mathrm{W}_{2}+\mathrm{W}_{3}
$$

214 where $\mathrm{W}_{1}$ is the energy received due to emission from the object, given by:

$$
\mathrm{W}_{1}=\tau \in \mathrm{E}_{\mathrm{b}}\left(\mathrm{T}_{\mathrm{obj}}\right)
$$


215 Here, $\varepsilon$ is the emissivity of the object, $\tau$ is the transmittance of the atmosphere, and $E_{b}\left(T_{o b j}\right)$ is the

216 blackbody emission at the object temperature. Also, $\mathrm{W}_{2}$ is the energy received due to the reflected emission

217 from surrounding sources, given by:

$$
\mathrm{W}_{2}=\tau(1-\epsilon) \mathrm{E}_{\mathrm{b}}\left(\mathrm{T}_{\text {sur }}\right)
$$

218 where (1-E) is the reflectivity of the object. Also, $\mathrm{W}_{3}$ is the emission from the atmosphere, given by:

$$
\mathrm{W}_{3}=(1-\tau) \mathrm{E}_{\mathrm{b}}\left(\mathrm{T}_{\mathrm{atm}}\right)
$$

219 where (1- $\tau)$ is the emissivity of the atmosphere. To calculate the correct target object, the IR camera 220 software needs inputs for the atmospheric temperature and attenuation, emissivity of the object, and the 221 surrounding temperature. These parameters can be assumed, measured, or obtained from tables. To obtain an accurate value of the emissivity of the molten $\mathrm{CuCl}$ in the temperature range of interest, an infrared camera (OPTRIS PI160) was calibrated with a type K thermocouple to measure the 224 temperature of molten salt contained in a vessel of $15 \mathrm{~cm}$ diameter. The specifications of the infrared camera 225 are listed in Table 1 . The type $\mathrm{K}$ thermocouple was integrated with a Labview data acquisition system 226 which could measure a voltage range of $\pm 80 \mathrm{mv}$ for the temperature range of $30-1000{ }^{\circ} \mathrm{C}$. The uncertainty 227 of the output of the type $\mathrm{K}$ thermocouple was $\pm 0.1 \%$ of the span, which is equivalent to $\pm 0.97{ }^{\circ} \mathrm{C}$. In the 228 emissivity calibration experiments, the molten salt in the vessel was about $1 \mathrm{~cm}$ thick to have good mixing, 229 and the thermocouple was placed $0.5 \mathrm{~cm}$ below the molten salt surface level.

As the infrared camera can measure the surface temperature, the molten salt immediately 231 surrounding the thermocouple was agitated to refresh the surface and make the surface temperature the 232 same as the temperature at $0.5 \mathrm{~cm}$ below the surface. The infrared camera was calibrated based on the 233 thermocouple reading. The $\mathrm{CuCl}$ existed simultaneously in both liquid and solid forms, several centimetres 234 from the thermocouple at the molten $\mathrm{CuCl}$ surface, because the surface was cooled down to its solid phase 235 to form a very thin solid layer on the molten salt surface. These co-existing two phases should give a 236 temperature reading of the melting point, $420^{\circ} \mathrm{C}$. In the experiment, the reading by the calibrated camera 237 was $421^{\circ} \mathrm{C}$, which lies in the range of measurement uncertainty. So it is believed that the emissivity 
determination is valid. One of the infrared images indicated the two-phase surface temperature. The temperature immediately adjacent to the thermocouple is presented in Fig. 2.

To measure the droplet temperature, the room temperature was controlled at $21{ }^{\circ} \mathrm{C}$ in each

241 experiment. As the droplet size is much smaller than the bulk molten stream, a high resolution thermal

242 imaging camera (Flir SC5600 camera) with Altair software was used for thermography of the molten

243 copper(I) chloride droplets. The technical specifications of the IR camera are shown in Table 2. The descent

244 of a droplet was tracked and compared with the thermal images. A visible light camera was used to record

245 the droplet during its descent in the gas stream and quenching at the water surface.

\subsection{X-ray diffraction system}

248 X-ray diffraction (XRD) was used to examine the composition change in the quench process. XRD is a versatile, non-destructive technique that reveals detailed information about the chemical composition of materials. When X-rays are incident on an atom of the droplet, they make the electron cloud move. The movement of these charges re-radiates the waves with the same frequency. This phenomenon is known as

252 Rayleigh scattering. These re-emitted wave fields interfere with each other, either constructively or

253 destructively, producing a diffraction pattern on the detector. The resulting wave interference pattern creates

254 a Bragg diffraction. The interference is constructive when the phase shift is a multiple of $2 \pi$. This condition 255 can be expressed by Bragg's law [50]:

$$
\mathrm{n} \lambda=2 \mathrm{~d} \sin \theta
$$

256 where $\mathrm{n}$ is an integer, $\lambda$ is the wavelength of the incident wave, $\mathrm{d}$ is the spacing between the planes in the 257 atomic lattice, and $\theta$ is the angle between the incident ray and the scattering planes.

258 Each crystalline material has a particular X-ray diffraction pattern. The number ofpeaks observed 259 is related to the symmetry of the unit cell. A unit cell with a higher symmetry has fewer diffraction peaks.

260 The spacings of the observed diffraction peaks are attributed to the repeat distances between planes of atoms 261 in the structure. The intensities of the peaks are identified with the types of atoms in the planes. The 262 scattering intensities for X-rays are related to the number of electrons in the atom. Heavy atoms scatter X- 
rays more effectively than light atoms. As stated earlier, three factors of an X-ray diffraction pattern (i.e.,

264 the number of peaks, positions of the peaks, and the intensities of the peaks) describe a unique X-ray pattern

265 for each substance.

A Philips XRD system was used. The basic components of the system are a PW 1830 HT generator,

267 a PW 1050 goniometer, PW 3710 control electronics, and X-Pert system software. During data collection,

268 the sample remains in a fixed situation and the X-ray source and detector are programmed to scan over a

269 range of $2 \theta$ values. Here, $2 \theta$ is the sum of the angle between the X-ray source and the sample and that

270 between the sample and the detector. Routinely, a $2 \theta$ range of $2^{\circ}$ to $60^{\circ}$ is acceptable to cover the most

271 useful part of the pattern. An appropriate scanning speed is selected based on a reasonable signal-to-noise

272 ratio for the diffraction peaks.

\section{6. Results and Discussion}

274 From the experiments, it was found that the molten stream at the tube exit breaks into several lumps of

275 irregular shapes, as shown in Figs. 3 and 4. The nozzle type droplet generation device was used to create

276 droplets with a more regular shape. Figure 5 shows the thermal image of a falling droplet using FLIR

277 SC5600. Each image was recorded per 0.01 second and the images were combined to form the full tracking

278 record.

Figure 6 shows the surface temperature of a near spherical droplet versus the flight time based on

280 the thermal images in Fig. 5. The droplets fall in ambient air at $21^{\circ} \mathrm{C}$. The initial temperature of the droplets

281 is about $504^{\circ} \mathrm{C}$. The experimental results represent the maximum temperature of the surface measured by

282 the infrared camera. Since the surface temperature is not uniform, and the droplet rotates during the flight,

283 the maximum surface temperature fluctuates during the flight. However, the maximum surface temperature

284 decreases in $0.11 \mathrm{~s}$. The analytical results are obtained from Eq. (12). The maximum difference between

285 the analytical and experimental results is less than 2\%. Figure 6 also shows that the droplet is not solidified

286 in the gas stream if the falling time is insufficient. This result was verified by the visible light-based camera. 
Figure 7 shows the thermal quench process of a droplet entering the water. The process includes impacting the water surface and forming steam bubbles, breaking of the bubbles, steam generation, and the disintegration of the droplet into many small pieces. It is believed that the small pieces were generated from

290 291 292 293 294 295 296

the evaporation of water and the droplet crust collapse at the interface of water and molten droplets. All droplets disintegrated into small flakes of solid $\mathrm{CuCl}$, even as the descent distance was $95 \mathrm{~cm}$ (see Fig. 8).

The quench phenomena suggests the avoidance of granulation processes for the solidified $\mathrm{CuCl}$, which is advantageous to the system integration of the oxygen production step, molten salt heat recovery process, and the hydrogen production step in the $\mathrm{Cu}-\mathrm{Cl}$ cycle. However, the steam generation and the droplet disintegration process may cause a steam explosion if a large amount of molten $\mathrm{CuCl}$ is introduced into water.

Copper(I) compounds may be unstable in contact with air or water. The possible chemical reactions between copper(I) chloride and water or air were examined. At a temperature of less than $750^{\circ} \mathrm{C}$, the following reaction can occur:

$$
2 \mathrm{CuCl}+1 / 2 \mathrm{O}_{2} \rightarrow \mathrm{Cu}_{2} \mathrm{O}+\mathrm{Cl}_{2}
$$

As the atmosphere contains moisture, the following reaction may occur:

$$
4 \mathrm{CuCl}+3 / 2 \mathrm{O}_{2}+3 \mathrm{H}_{2} \mathrm{O} \rightarrow 2 \mathrm{Cu}_{2}(\mathrm{OH})_{3} \mathrm{Cl}+\mathrm{Cl}_{2}
$$

The copper(I) chloride may also react with water in the presence of oxygen as follows:

$$
6 \mathrm{CuCl}+3 / 2 \mathrm{O}_{2}+7 \mathrm{H}_{2} \mathrm{O} \rightarrow 2 \mathrm{Cu}_{2}(\mathrm{OH})_{3} \mathrm{Cl}+2\left[\mathrm{CuCl}_{2} \cdot 2 \mathrm{H}_{2} \mathrm{O}\right]
$$

As stated earlier, two sets of experiments were performed at different conditions. In the first set of experiments, the solidified $\mathrm{CuCl}$ was taken from the water vessel and exposed to air (Fig. 9). The color of the material changes from gray to green. Figures 10 and 11 show the x-ray diffraction results for two experiments. As expected, $\mathrm{Cu}_{2}(\mathrm{OH})_{3} \mathrm{Cl}$ and $\mathrm{CuCl}_{2} \cdot 2 \mathrm{H}_{2} \mathrm{O}$ are observed.

In the second set of experiments, solidified $\mathrm{CuCl}$ is kept in water in a small container, in a nitrogen glove box. Therefore, the material is not in contact with oxygen. In this case, the color of the material remains gray. The x-ray diffraction results are presented in Figures 12 and 13 for two experiments. It is 
observed that copper(I) chloride does not react with water in the absence of oxygen. It is also concluded that the molten droplets of $\mathrm{CuCl}$ do not react with air during the droplet descent. It is believed that this

311 occurs because the contact time between the droplets and air is very small. For a large industrial scale 312 quench process, it is suggested to drop molten $\mathrm{CuCl}$ droplets into water in an inert atmosphere to avoid 313 chemical reactions. Also, the water might be deoxygenated.

314 The uncertainty $(\mathrm{U})$ of the experimental results is determined by [51]:

$$
\mathrm{U}=\sqrt{\mathrm{B}^{2}+\mathrm{P}^{2}}
$$

315 where B and P represent the bias and precision errors, respectively. The bias error in temperature

316 measurement by the thermal imaging system is \pm 0.01 . The precision error is double the standard deviation

317 of the measured data. A sample of 30 measurements was considered, and the precision error was calculated 318 as \pm 0.02 . The measurement uncertainty was then determined as \pm 0.02 .

\section{Conclusions}

321 Hydrogen can be used as an energy carrier and storage medium along with renewable energy resources.

322 Among various methods of hydrogen production, the copper-chlorine thermochemical cycle has been shown

323 to be a promising method for production of hydrogen due to its lower temperature requirement for heat 324 supply compared to other thermochemical cycles. However, it is essential to improve the overall thermal 325 efficiency of the cycle by effectively recovering heat within the cycle and reducing the net heat requirement 326 of the cycle. Molten salt exiting the oxygen production step of the cycle has a temperature of about $530^{\circ} \mathrm{C}$.

327 Heat recovered from cooling and solidifying of molten $\mathrm{CuCl}$ may be used to produce superheated steam 328 required in the hydrolysis step of the cycle.

329 In this paper, a direct contact process for heat recovery from molten salt in the $\mathrm{Cu}-\mathrm{Cl}$ cycle of 330 hydrogen production was studied experimentally and analytically. The molten droplets exiting the nozzle fall 331 through air and eventually quenched into a water vessel. The surface temperature of the droplet during the 332 flight was measured by an infrared camera. The fundamental phenomena such as droplet surface 
333 temperature during descent, breaking of molten droplets in water, and the composition change in the quench

334 process were presented. The potential reactions between copper(I) chloride and water or air were

335 investigated through the experiments. The results show that $\mathrm{CuCl}$ does not react with water in the absence

336 of oxygen. Therefore, a direct contact process is feasible for recovering heat from molten $\mathrm{CuCl}$ in the

337 copper-chlorine cycle. It is feasible to quench the molten salt droplets for an efficient heat recovery process

338 without introducing any material imbalance in the process integration.

340 Acknowledgements

341 Financial support from the Atomic Energy of Canada Limited (AECL), Natural Sciences and Engineering

342 Research Council of Canada (NSERC), and Ontario Research Fund (ORF) is gratefully acknowledged.

343 Professor Williams from the University of Western Sydney and Professor Frost from Queensland

344 University of Technology are also thankfully acknowledged for their helpful assistance on the chemical 345 reactions.

346

$347 \quad$ Nomenclature

$\begin{array}{ll}A & \text { Surface area }\left[\mathrm{m}^{2}\right] \\ B & \text { Bias } \\ C_{D} & \text { Drag coefficient } \\ c_{p} & \text { Specific heat at constant pressure }[\mathrm{J} / \mathrm{kg} \cdot \mathrm{K}] \\ d & \text { Droplet diameter }[\mathrm{mm}] \\ E_{b} & \text { Blackbody emissivity power }[\mathrm{W}] \\ g & \text { Gravitational acceleration }\left[\mathrm{m} / \mathrm{s}^{2}\right] \\ h_{c} & \text { Convection heat transfer coefficient }\left[\mathrm{W} / \mathrm{m}^{2} \cdot \mathrm{K}\right] \\ k & \text { Thermal conductivity }[\mathrm{W} / \mathrm{m} . \mathrm{K}] \\ m & \text { Mass }[\mathrm{kg}]\end{array}$




$\begin{array}{ll}N u & \text { Nusselt number } \\ P & \text { Precision } \\ P r & \text { Prandtl number } \\ \dot{q}_{c} & \text { Convective heat transfer rate [W] } \\ R e & \text { Reynolds number } \\ T & \text { Temperature }\left[{ }^{\circ} \mathrm{C}\right] \\ t & \text { Time [s] } \\ U & \text { Uncertainty } \\ v & \text { Velocity }[\mathrm{m} / \mathrm{s}]\end{array}$

$348 \quad$ Greek symbols

$\begin{array}{ll}\alpha & \text { Thermal diffusivity }\left[\mathrm{m}^{2} / \mathrm{s}\right] \\ \beta & \text { Fixed (bias) error } \\ \delta_{k} & \text { Measurement error } \\ \epsilon & \text { Emissivity } \\ \theta & \text { Angle between the incident ray and the scattering planes [rad] } \\ \lambda & \text { Wavelength of the incident wave }[\mathrm{m}] \\ \rho & \text { Density }\left[\mathrm{kg} / \mathrm{m}^{3}\right]\end{array}$

\section{Subscripts}

$\begin{array}{ll}\text { atm } & \text { Atmosphere } \\ d & \text { Droplet } \\ g & \text { Gas } \\ \text { obj } & \text { Object } \\ s & \text { Surface } \\ \text { sur } & \text { Surroundings } \\ \infty & \text { Ambient }\end{array}$




\section{References}

351 [1] T. N. Veziroglu, S. Sahin, “21 $1^{\text {st }}$ century’s energy”, Energy Conversion and Management, Vol. 352 49, pp. 1820-1831, 2008.

353 [2] R. L. Nersesian, Energy for the $21^{\text {st }}$ century: A comprehensive guide to conventional and alternative 354 sources, Second Edition. M. E. Sharpe, Armonk, NY, 2010.

355 [3] A. F. Ghoniem, "Needs, resources and climate change: Clean and efficient conversion technologies", 356 Progress in Energy and Combustion Science, Vol. 37, pp. 15-51, 2011.

357 [4] P. Ekins, Hydrogen energy: economic and social challenges, Earthscan, London, UK, 2010.

358 [5] K. Christopher, R. Dimitrios, “A review on exergy comparison of hydrogen production methods from 359 renewable energy sources”, Energy and Environmental Science, Vol. 5, pp. 6640-6651, 2012.

360 [6] A. Midilli, I. Dincer, "Hydrogen as a renewable and sustainable solution in reducing global fossil fuel 361 consumption”, International Journal of Hydrogen Energy, Vol. 33, pp. 4209-4222, 2008.

362 [7] J. G. G. Clua, R. J. Mantz, H. De Battista“Evaluation of hydrogen production capabilities of a grid363 assisted wind-H2 system”, Applied Energy, Vol. 88, pp. 1857-1863, 2011.

364 [8] D. Lu, B. Wang, Y. Wang, H. Zhou, Q. Liang, Y. Peng, T. Roskilly “Optimal operation of cascade 365 hydropower stations using hydrogen as storage medium”, Applied Energy, Vol. 137, pp. 56-63, 2015.

366 [9] D. Kroniger, R. Madlener "Hydrogen storage for wind parks: A real options evaluation for an optimal 367 investment in more flexibility”, Applied Energy, Vol. 136, pp. 931-946, 2014.

368 [10] R. Sarrias-Mena, L. M. Fernandez-Ramirez, C. A. Garcia-Vazquez, F. Jurado "Electrolyzer models 369 for hydrogen production from wind energy systems”, International Journal of Hydrogen Energy, Vol. 40, $370 \quad$ pp. 2927-2938, 2015.

371 [11] R. Dell, Clean energy. Royal Society of Chemistry. London, UK, 2004.

372 [12] R. Kothari, D. Buddhiand, R. L. Sawhney, "Comparison of environmental and economic aspects of 373 various hydrogen production methods”, Renewable and Sustainable Energy Reviews, Vol. 12, pp. 553-563, 3742008. 
[13] H. Li, G. Tan, W. Zhang, S. Suppiah, "Development of direct resistive heating method for $\mathrm{SO}_{3}$ decomposition in the S-I cycle for hydrogen production”, Applied Energy, Vol. 93, pp. 59-64, 2012.

[14] S. Ghandehariun, G. F. Naterer, I. Dincer, M. A. Rosen, "Solar thermochemical plant analysis for hydrogen production with the copper-chlorine cycle”, International Journal of Hydrogen Energy, Vol. 35, pp. 8511-8520, 2010.

[15] B. S. Kwak, J. Chae, M. Kang, "Design of a photochemical water electrolysis system based on a Wtyped dye-sensitized serial solar module for high hydrogen production”, Applied Energy, Vol. 125, pp. 189196, 2014.

[16] B. Han, S. M. Steen III, J. Mo, F. Zhang “Electrochemical performance modeling of a proton exchange membrane electrolyzer cell for hydrogen energy”, International Journal of Hydrogen Energy, Vol. 40, pp. 7006-7016, 2015.

[17] D. Penchini, G. Cinti, G. Discepoli, U. Desideri “Theoretical study and performance evaluation of hydrogen production by 200 W solid oxide electrolyzer stack”, International Journal of Hydrogen Energy, Vol. 39, pp. 9457-9466, 2014.

[18] M. A. Rosen, “Advances in hydrogen production by thermochemical water decomposition: A review”, Energy, Vol. 35, pp. 1068-1076, 2010.

[19] Y. Zhang, H. Yang, J. Zhou, Z. Wang, J. Liu, K. Cen, “Detailed kinetic modeling of homogeneous $\mathrm{H}_{2} \mathrm{SO}_{4}$ decomposition in the sulfur-iodine cycle for hydrogen production”, Applied Energy, Vol. 130, pp. 396-402, 2014.

[20] S. Ghandehariun, Z. Wang, M. A. Rosen, G. F. Naterer, "Reduction of hazards from copper (I) chloride in a Cu-Cl thermochemical hydrogen production plant”, Journal of Hazardous Materials, Vol. 229-230, pp. 48-56, 2012.

[21] L. Roca, A. de la Calle, L. J. Yebra, "Heliostat-field gain-scheduling control applied to a two-step solar hydrogen production plant”, Applied Energy, Vol. 103, pp. 298-305, 2013.

[22] X. Zhang, H. Jin, “Thermodynamic analysis of chemical-looping hydrogen generation”, Applied Energy, Vol. 112, pp. 800-807, 2013. 
401 [23] S. Ghandehariun, M. Talimi, G. F. Naterer, M. A. Rosen, “Analysis of the hazards for the molten 402 cuprous chloride pouring operation in an industrial hydrogen production facility”, Int. J. of Energy 403 Research, Vol. 37, pp. 358-369, 2013.

404 [24] C. Huang, A. T. Raissi, "Analysis of sulfure iodine thermochemical cycle for solar hydrogen 405 production. Part I: Decomposition of sulfuric acid”, Solar Energy, Vol. 78, pp. 632-646, 2005.

406 [25] W. Xinxin, O. Kaoru, “Thermochemical water splitting for hydrogen production utilizing nuclear heat 407 from an HTGR”, Tsinghua Science and Technology, Vol. 10, pp. 270-276, 2005.

408 [26] R. Liberatore, M. Lanchi, A. Giaconia, P. Tarquini, "Energy and economic assessment of an industrial 409 plant for the hydrogen production by water-splitting through the sulfur-iodine thermochemical cycle 410 powered by concentrated solar energy”, International Journal of Hydrogen Energy, Vol. 37, 9550-9565, 4112012.

412 [27] F. Varsano, M. A. Murmura, B. Brunetti, F. Padella, A. La Barbera, C. Alvani, M. C. Annesini 413 "Hydrogen production by water splitting on manganese ferrite-sodium carbonate mixture: Feasibility tests 414 in a packed bed solar reactor-receiver”, International Journal of Hydrogen Energy, Vol. 39, pp. 20920$41520929,2014$.

416 [28] C. Canavesio, H. E. Nassini, A. E. Bohe "Evaluation of an iron-chlorine thermochemical cycle for 417 hydrogen production”, International Journal of Hydrogen Energy, Vol. 40, pp. 8620-8632, 2015.

418 [29] R. Xu, T. F. Wiesner "Conceptual design of a two-step solar hydrogen thermochemical cycle with 419 thermal storage in a reaction intermediate”, International Journal of Hydrogen Energy, Vol. 39, pp. 12457$420 \quad 12471,2014$.

421 [30] M. A. Lewis, J. G. Masin, P. A. O’Hare, “Evaluation of alternative thermochemical cycles, Part I: The 422 methodology”, International Journal of Hydrogen Energy, Vol. 34, pp. 4115-4124, 2009.

423 [31] M. A. Lewis, J. G. Masin, “The evaluation of alternative thermochemical cycles - Part II: The down424 selection process”, International Journal of Hydrogen Energy, Vol. 34, pp. 4125-4135, 2009. 
425

426

427

428

429

430

431

432

433

434

435

436

437

438

439

440

441

442

443

444

445

446

447

448

449

[32] M. A. Lewis, M. S. Ferrandon, D. F. Tatterson, P. Mathias, "Evaluation of alternative thermochemical cycles - Part III further development of the Cu-Cl cycle”, International Journal of Hydrogen Energy, Vol. 34, pp. 4136-4145, 2009.

[33] I. Dincer, M. T. Balta, "Potential thermochemical and hybrid cycles for nuclear-based hydrogen production”, International Journal of Energy Research, Vol. 35, pp. 123-137, 2011.

[34] Z. L. Wang, G. F. Naterer, K. S. Gabriel, R. Gravelsins, V. N. Daggupati, “Comparison of different copper-chlorine thermochemical cycles for hydrogen production”, International Journal of Hydrogen Energy, Vol. 34, pp. 3267-3276, 2009.

[35] M. Serban, M. A. Lewis, J. K. Basco, “Kinetic study of the hydrogen and oxygen production reactions in the copper-chloride thermochemical cycle”, AIChE 2004 Spring National Meeting, New Orleans, LA, 2004.

[36] G. F. Naterer, S. Suppiah, M. Lewis, K. Gabriel, I. Dincer, M. A. Rosen, M. Fowler, G. Rizvi, E. B. Easton, B. M. Ikeda, M. H. Kaye, L. Lu, I. Pioro, P. Spekkens, P. Tremaine, J. Mostaghimi, A. Avsec, J. Jiang, "Recent Canadian advances in nuclear-based hydrogen production and the thermochemical $\mathrm{Cu}-\mathrm{Cl}$ cycle”, International Journal of Hydrogen Energy, Vol. 34, pp. 2901-2917, 2009.

[37] G. F. Naterer, S. Suppiah, L. Stolberg, M. Lewis, M. Ferrandon, Z. Wang, I. Dincer, K. Gabriel, M. A. Rosen, E. Secnik, E. B. Easton, L. Trevani, I. Pioro, P. Tremaine, S. Lvov, J. Jiang, “Canada’s program on nuclear hydrogen production and the thermochemical Cu-Cl cycle.”, International Journal of Hydrogen Energy, Vol. 36, pp. 15472-15485, 2011.

[38] G. F. Naterer, S. Suppiah, L. Stolberg, M. Lewis, M. Ferrandon, Z. Wang, I. Dincer, K. Gabriel, M. A. Rosen, E. Secnik, E. B. Easton, L. Trevani, I. Pioro, P. Tremaine, S. Lvov, J. Jiang, "Clean hydrogen production with the $\mathrm{Cu}-\mathrm{Cl}$ cycle - Progress of international consortium, I: Experimental unit operations”, International Journal of Hydrogen Energy, Vol. 36, pp. 15486-15501, 2011.

[39] G. F. Naterer, S. Suppiah, L. Stolberg, M. Lewis, M. Ferrandon, Z. Wang, I. Dincer, K. Gabriel, M. A. Rosen, E. Secnik, E. B. Easton, L. Trevani, I. Pioro, P. Tremaine, S. Lvov, J. Jiang, "Clean hydrogen 
production with the $\mathrm{Cu}-\mathrm{Cl}$ cycle - Progress of international consortium, II: Simulations, thermochemical data and materials”, International Journal of Hydrogen Energy, Vol. 36, pp. 15486-15501, 2011.

452 [40] C. Zamfirescu, I. Dincer, G. F. Naterer, "Thermophysical properties of copper compounds in the 453 copper-chlorine thermochemical water splitting cycles”, International Journal of Hydrogen Energy, Vol. 454 35, pp. 4839-4852, 2010.

455 [41] A. Ozbilen, I. Dincer, M. A. Rosen, "Environmental evaluation of hydrogen production via 456 thermochemical water splitting using the $\mathrm{Cu}-\mathrm{Cl}$ cycle: A parametric study, International Journal of 457 Hydrogen Energy, Vol. 36, pp. 9514-9528, 2011.

458 [42] M. S. Ferrandon, M. A. Lewis, D. F. Tatterson, A. Gross, D. Doizi, L. Croize, V. Dauvois, J. L. Roujou, 459 Y. Zanella, P. Carles, "Hydrogen production by a $\mathrm{Cu}-\mathrm{Cl}$ thermochemical cycle: Investigation of the key 460 step of hydrolysing $\mathrm{CuCl}_{2}$ to $\mathrm{Cu}_{2} \mathrm{OCl}_{2}$ and $\mathrm{HCl}$ using a spray reactor”, International Journal of Hydrogen 461 Energy, Vol. 35, pp. 992-1000, 2010.

462 [43] G. F. Naterer, V. N. Daggupati, G. Marin, K. S. Gabriel, Z. L. Wang, "Thermochemical hydrogen 463 production with a copper-chlorine cycle, II: Flashing and drying of aqueous cupric chloride”, International 464 Journal of Hydrogen Energy, Vol. 33, pp. 5451-5459, 2008.

465 [44] G. F. Naterer, K. Gabriel, Z. L. Wang, V. N. Daggupati, R. Gravelsins, "Thermochemical hydrogen 466 production with a copper-chlorine cycle. I: Oxygen release from copper oxychloride decomposition”, 467 International Journal of Hydrogen Energy, Vol. 33, pp. 5439-5450, 2008.

468 [45] S. Ghandehariun, M. A. Rosen, G. F. Naterer, Z. Wang, "Pinch analysis for recycling thermal energy 469 in the Cu-Cl cycle”, International Journal of Hydrogen Energy, Vol. 37, pp. 16535-16541, 2012.

470 [46] S. Ghandehariun, M. A. Rosen, G. F. Naterer, Z. Wang, “Comparison of molten salt heat recovery 471 options in the Cu-Cl cycle of hydrogen production”, International Journal of Hydrogen Energy, Vol. 36, 472 pp. 11328-11337, 2011.

473 [47] S. Ghandehariun, G. F. Naterer, M. A. Rosen, Z. Wang, "Indirect contact heat recovery with 474 solidification in thermochemical hydrogen production”, Energy Conversion and Management, Vol. 82, pp. $475 \quad$ 212-218, 2014. 
476 [48] R. Clift, M. E. Weber, J. R. Grace, Bubbles, drops, and particles, Academic Press, N.Y., 1978.

477 [49] W. Ranz, W. Marshall, “Evaporation from drops”, Chemical Engineering Progress, Vol. 48, pp. 141-

$478 \quad 146,1952$.

479 [50] B. D. Cullity, Elements of x-ray diffraction, Addison-wesley Publishing Company, Massachusetts,

4801956.

481 [51] S. J. Kline, F. A. McClintock, “Describing uncertainties in single-sample experiments”, Mechanical $482 \quad$ Engineering, Vol. 75, pp. 3-8, 1953.

483

484

485

Table 1. Technical specifications of Optris PI160

\begin{tabular}{|c|c|}
\hline Detector & FPA, uncooled \\
\hline Spectral range & $7.5-13 \mu \mathrm{m}$ \\
\hline Optical resolution & $160 \times 120$ \\
\hline Frame rate & $120 \mathrm{~Hz}$ \\
\hline Temperature range & $150-900^{\circ} \mathrm{C}$ \\
\hline Accuracy & $\pm 2^{\circ} \mathrm{C}$ or $\pm 2 \%$ \\
\hline
\end{tabular}

Table 2. Technical specifications of Flir Sc5600

\begin{tabular}{|c|c|}
\hline Sensor type & InSb \\
\hline Waveband & $3-5 \mu \mathrm{m}$ \\
\hline Pixel resolution & $640 \times 512$ \\
\hline Pitch & $15 \mu \mathrm{m}$ \\
\hline Cooler & Close cycle Stirling cooler \\
\hline Maximum frame rate (full frame) & $100 \mathrm{~Hz}$ \\
\hline Integration time & $200 \mathrm{~ns}$ to $20 \mathrm{~ms}$ \\
\hline Temperature measurement range & $5-1500^{\circ} \mathrm{C}$ \\
\hline Temperature measurement accuracy & $\pm 1^{\circ} \mathrm{C}$ or $\pm 1 \%$ \\
\hline
\end{tabular}




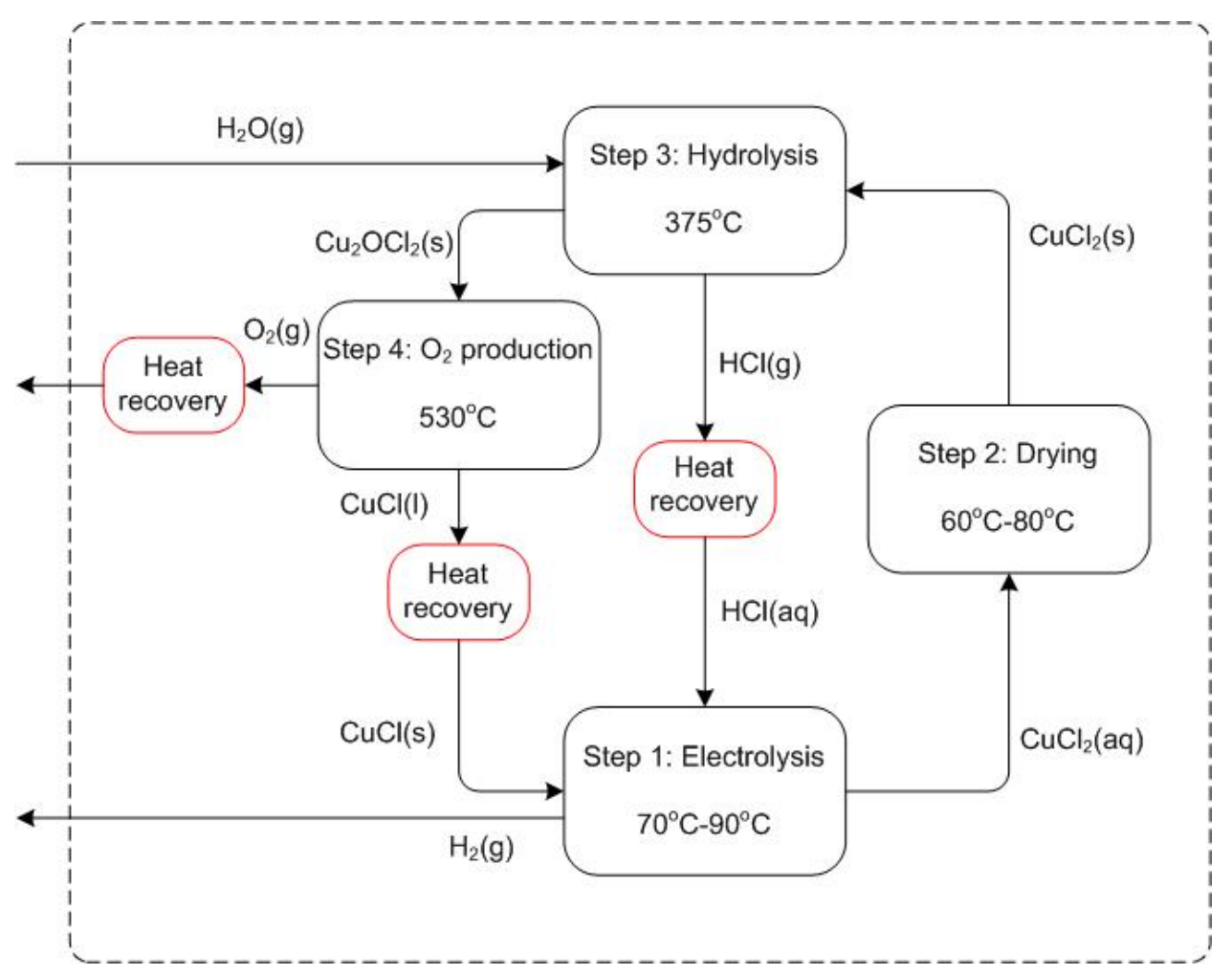




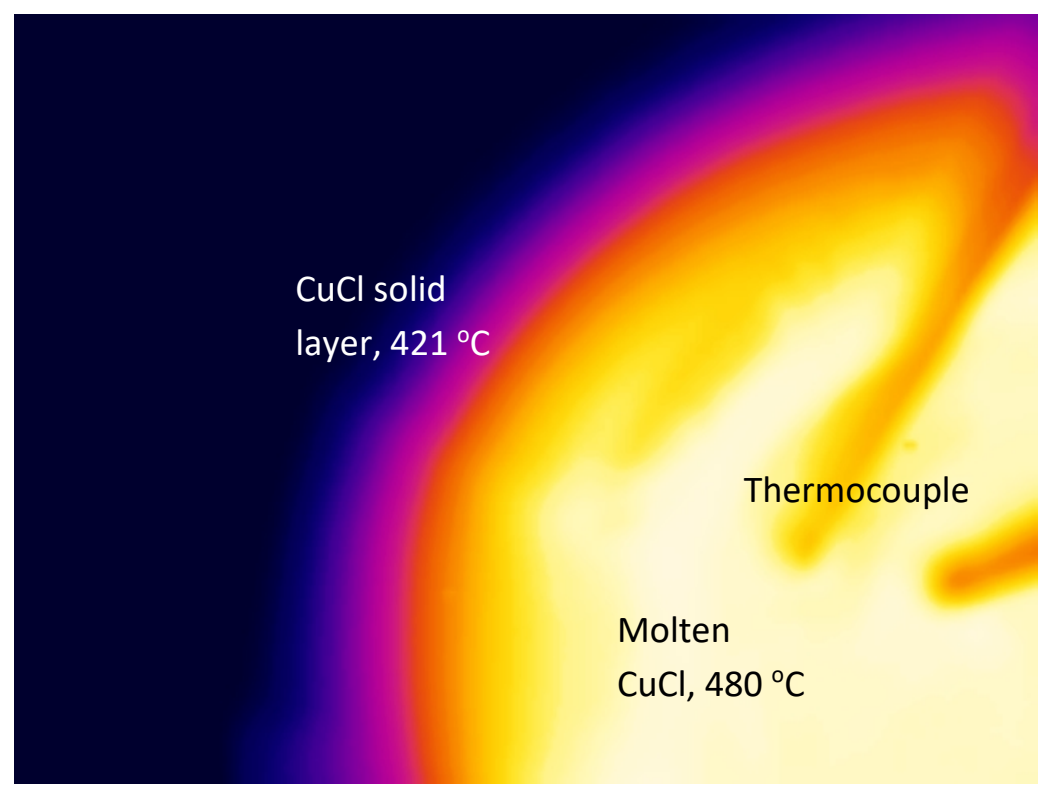

Fig. 2 Temperature measurement of $\mathrm{CuCl}$ using Optris PI160 thermal imager 504 505 506 507

\section{$\uparrow 493.0^{\circ} \mathrm{C}$}



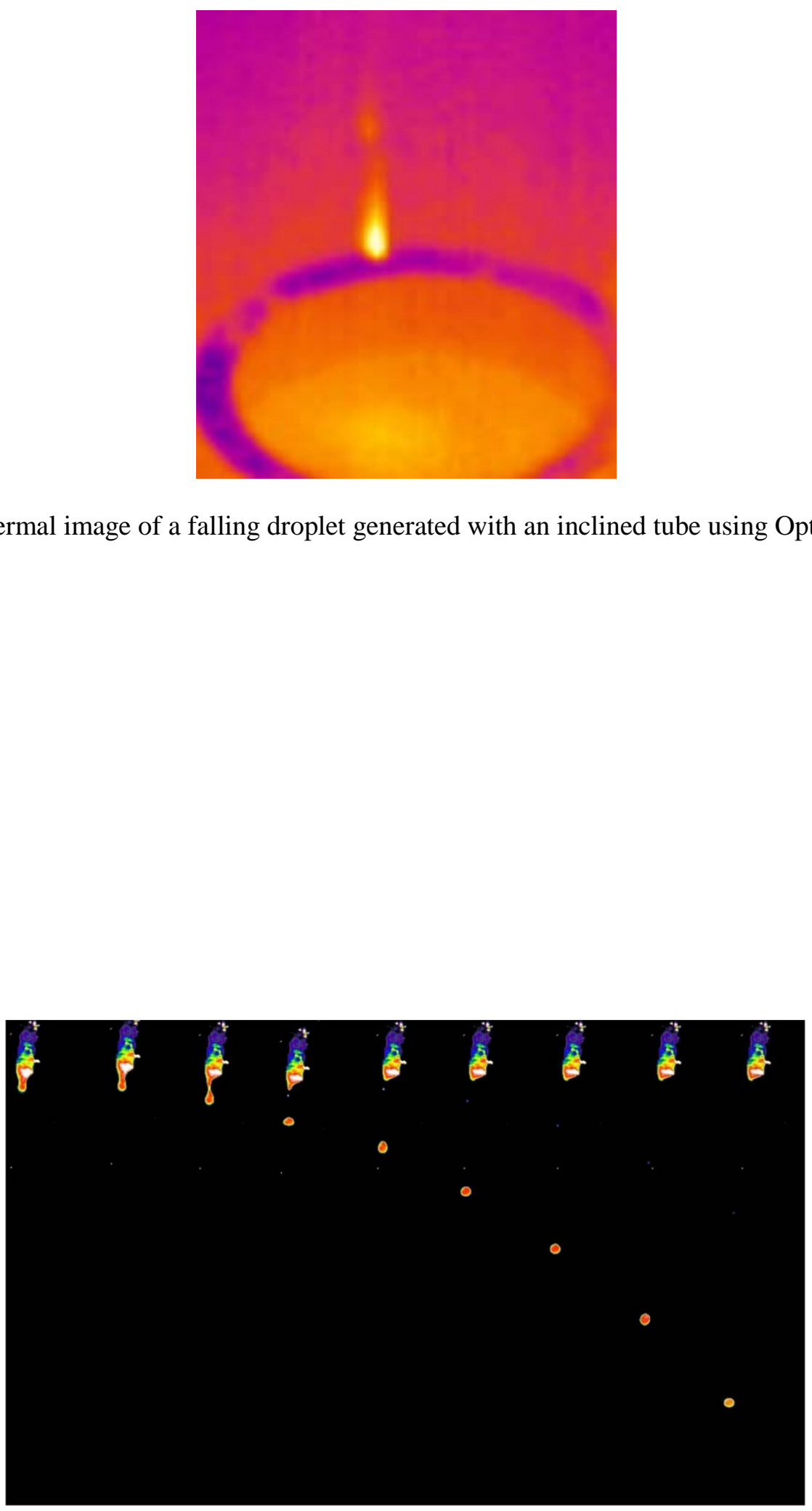


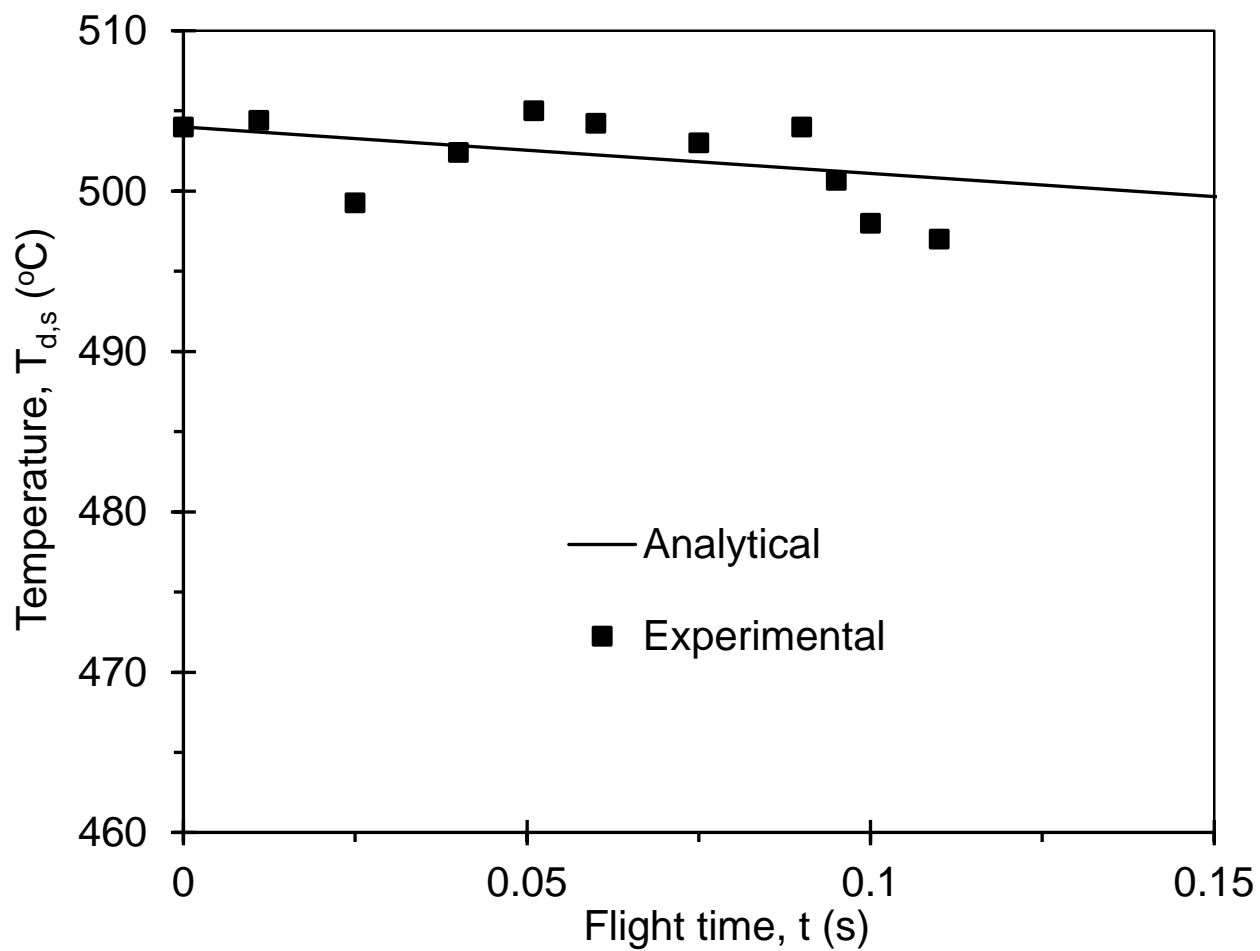

525

526

527

528

529

530

531

Fig. 6 Droplet temperature versus flight time

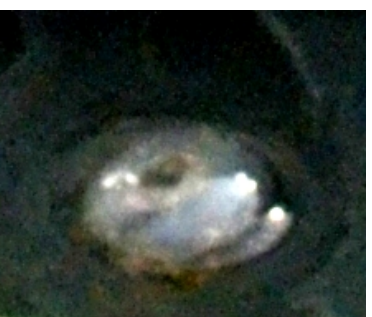

(a) $\mathrm{CuCl}$ molten droplet hits the water surface and forms a steam bubble

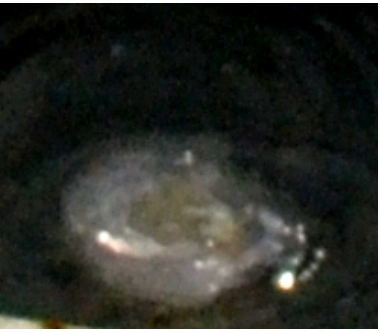

(b) $\mathrm{CuCl}$ droplet leaves the water surface 


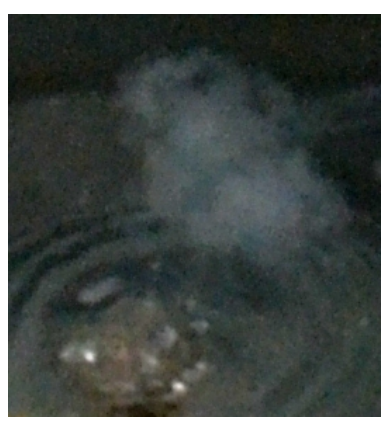

(c) Steam bubble breaks to release steam

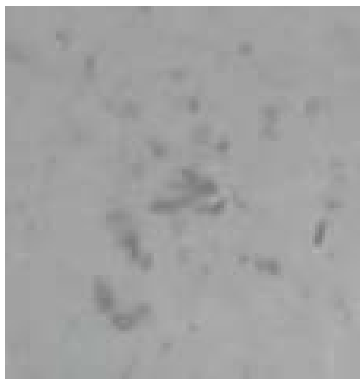

(d) Droplet breaks into many flakes

Fig. 7 Quenching of a droplet in water

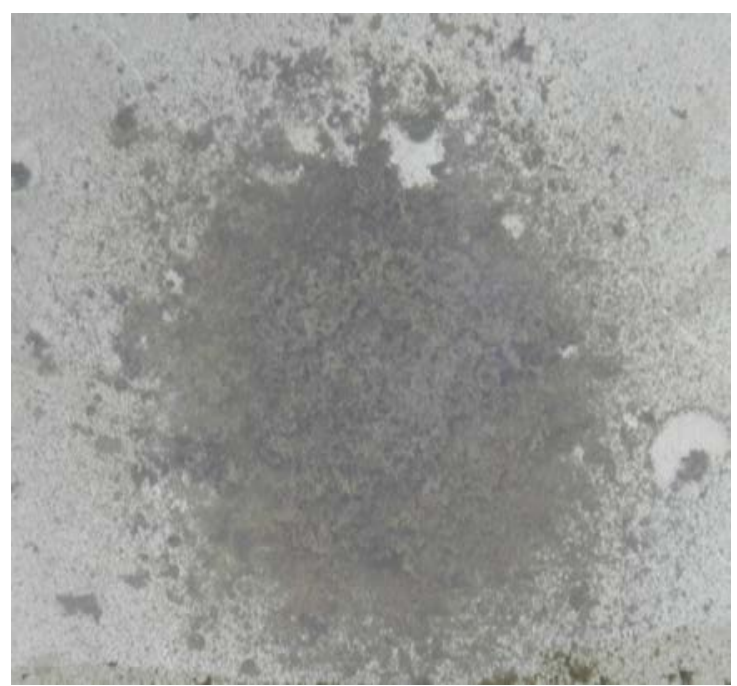

Fig. $8 \mathrm{CuCl}$ droplets break into many small flakes 

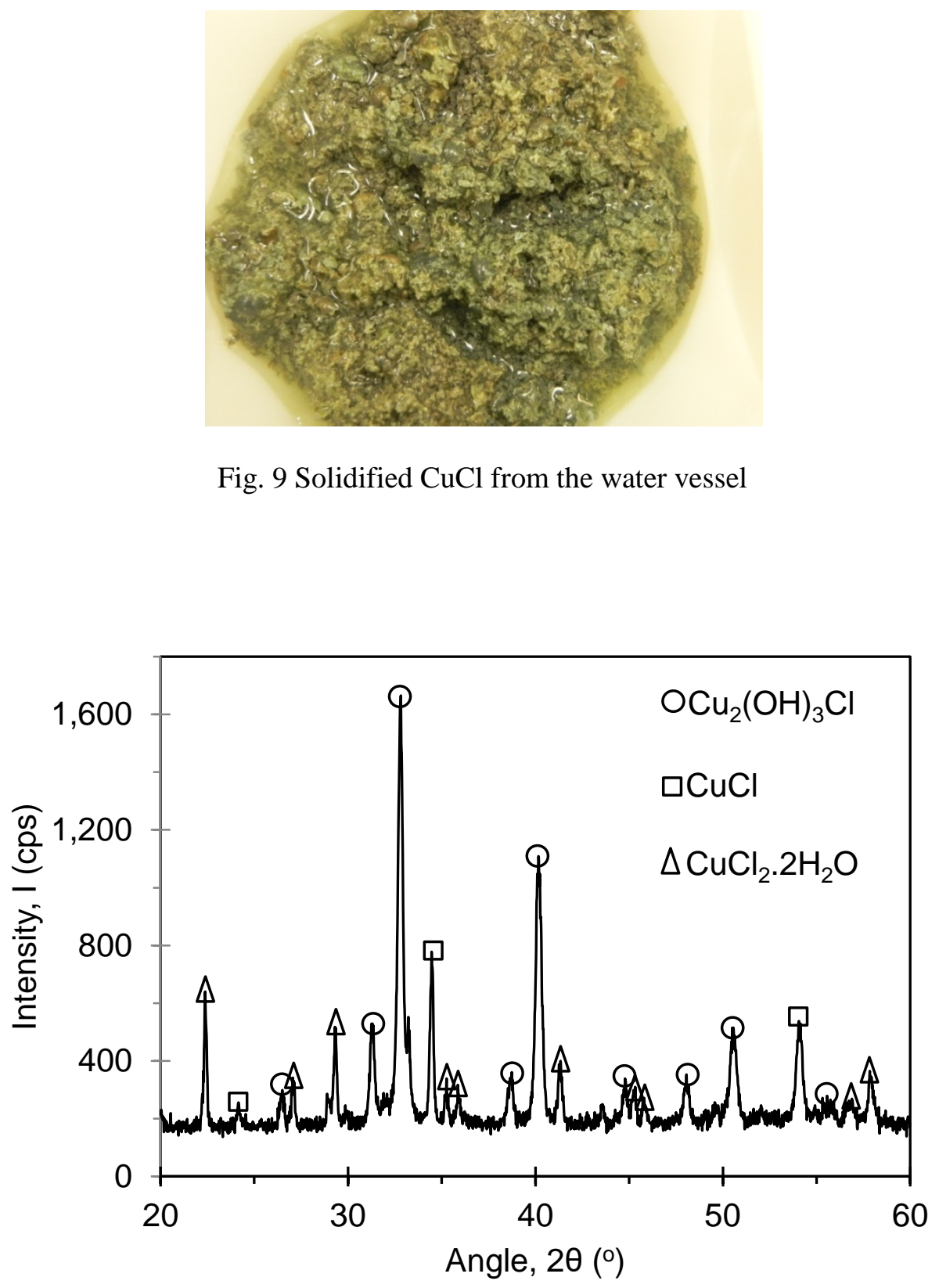

Fig. $10 \mathrm{X}$-ray diffraction results for $\mathrm{CuCl}$ in contact with air and water 


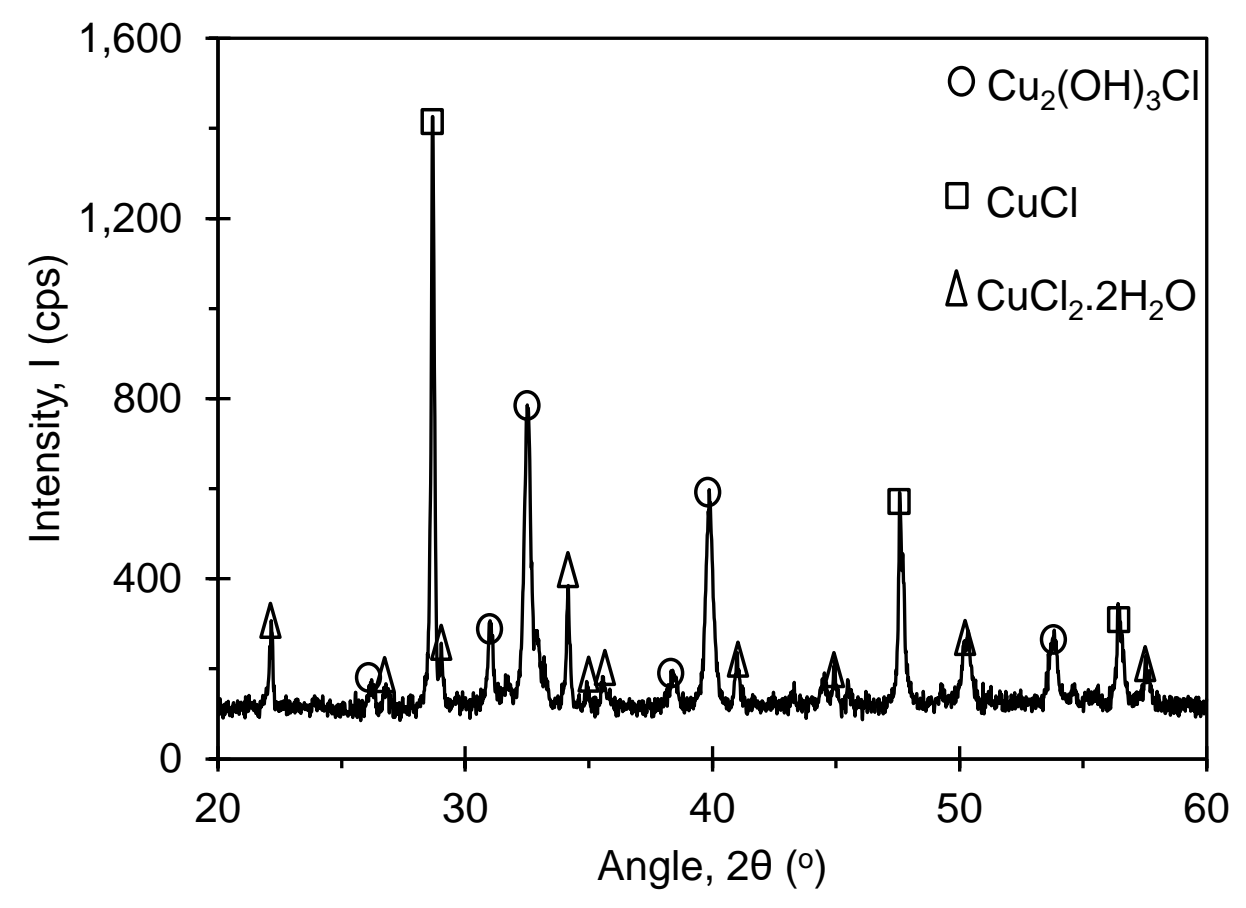

553

554

Fig. $11 \mathrm{X}$-ray diffraction results for $\mathrm{CuCl}$ in contact with air and water

555

556

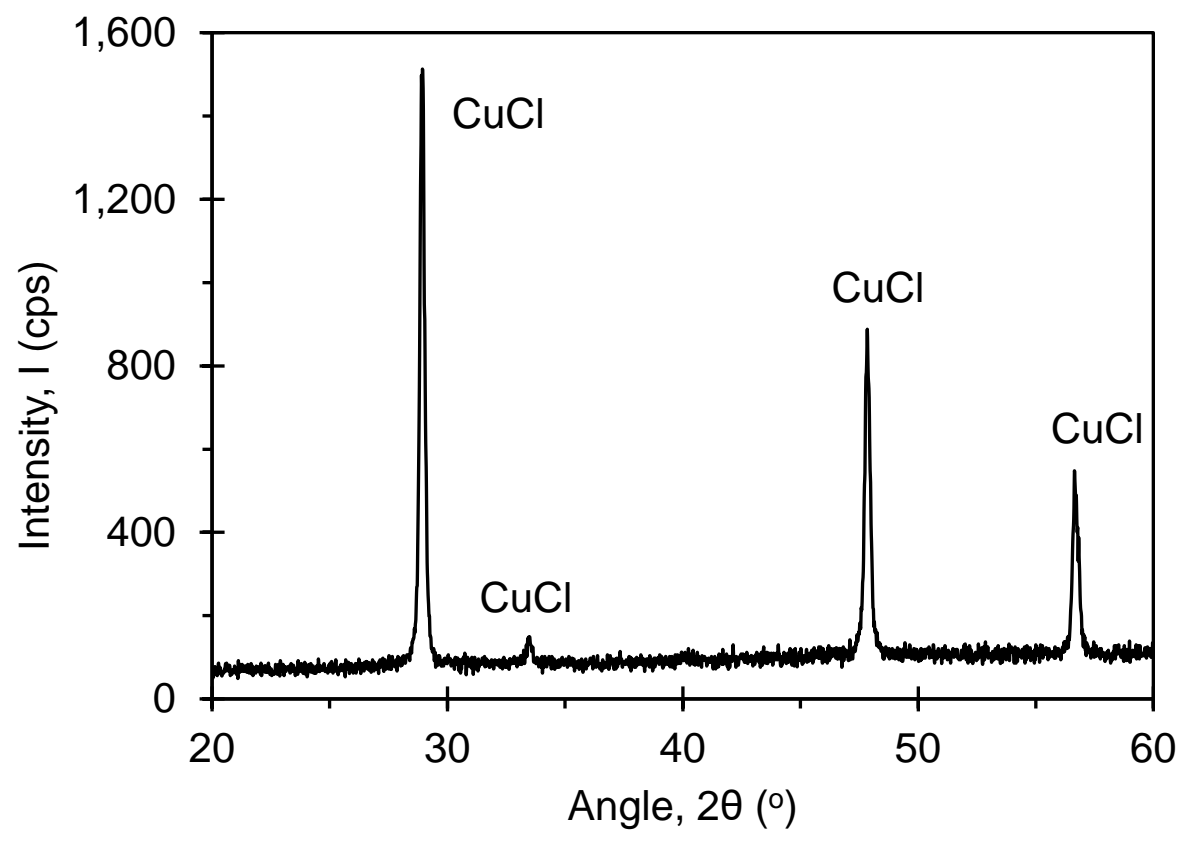

Fig. $12 \mathrm{X}$-ray diffraction results for $\mathrm{CuCl}$ in contact with water 


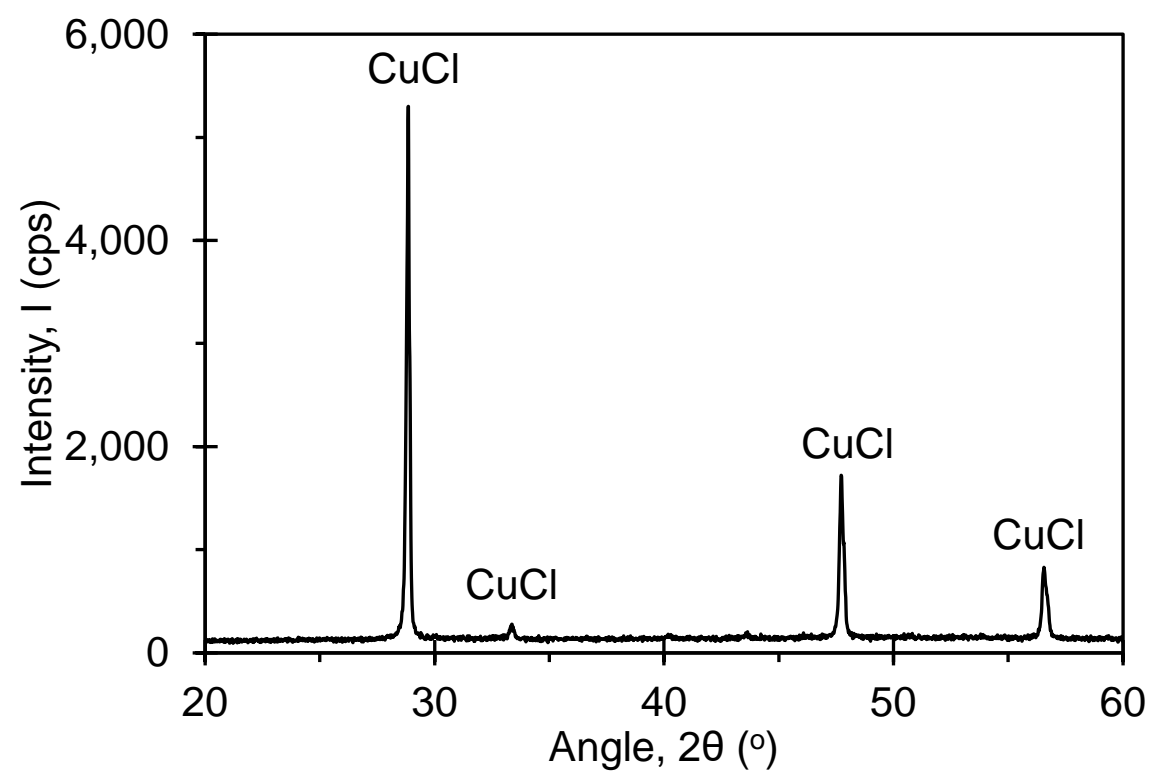

Fig. $13 \mathrm{X}$-ray diffraction results for $\mathrm{CuCl}$ in contact with water 